\title{
EVALUATION OF A BIO-ASSAY OF ETHER EXTRACTS FROM CORN (ZEA MAYS L.) AS A MEANS OF SCREENING INBREDS FOR RESISTANCE TO ROOT AND STALK ROT
}

\author{
N. J. Whitney ${ }^{2}$ and C. G. Mortimore \\ Canada Department of Agriculture, Harrow, Ontario
}

[Received for publication October 13, 1961]

\begin{abstract}
In bio-assay tests ether extracts of the roots and of the stalks of both resistant and susceptible corn inbreds inhibited the growth of Fusarium moniliforme Sheld. and Gibberella zeae (Schw.) Petch, the level of inhibition varying over the season. However, the extracts of the resistant and susceptible inbreds did not differ consistently in their ability to inhibit fungus growth on any given date. Thus, this bio-assay method cannot be used to evaluate inbreds for resistance to root and stalk rot.
\end{abstract}

\section{INTRODUCTION}

In 1945, Johann and Dickson (2) reported on an ether-soluble substance in cornstalks which retarded growth of Diplodia zeae in culture. From 1955 until 1959 other workers reported on antifungal substances in corn and their effect on various micro-organisms. Loomis, Beck, and Stauffer (3) found resistance factors in corn which were effective against the European corn borer, Pyrausta nubilalis (Hubn.), Penicillium crysogenum, and bacteria. Virtanen and Hietala (5) and Virtanen, Hietala, and Wahlroos (6) isolated antifungal factors from wheat, naize, and rye, which inhibited Fusarium sp., Penicillium sp., Aspergillus sp., Sclerotinia trifoliorum, Torula sp., and bacteria (Escherichia coli, and Staphylococcus sp.). Messiaen (4) reported a correlation between high sugar content in corn stalks and resistance to infection by anthracnose, Colletotrichum graminis. Barnes (1) found a fungal inhibitor in corn that was fungistatic against Gibberella zeae. Whitney and Mortimore $(8,9)$ published on the antifungal substance, 6-methoxybenzoxazolinone, in corn and its effect on Gibberella zeae, Fusarium moniliforme, Diplodia zeae, and Pyrenocbaeta terrestris. They suggested also (7) that resistance to root and stalk rot is in the roots.

The above findings suggest that resistance to root and stalk rot of corn may be correlated with a particular biochemical property of the plant. Therefore, experiments were conducted to determine if resistance to root and stalk rot could be correlated with ether-soluble extracts from corn stalks or roots, thereby, providing the basis for a screening technique. The present paper presents the findings of investigations conducted in 1959 and 1960.

\section{WATERIAIS AND METHODS}

Normal and barren ${ }^{3}$ plants of the following four dent inbreds were grown for this investigation: W37A and $\mathrm{CH} 3$ (susceptible); $\mathrm{CH} 9$ and $\mathrm{B} 14$ (resistant). Barren plants were obtained by bagging the ear shoots prior to silk emergence.

Samples of roots and stalks of normal plants were taken for extraction at progressive developmental stages of the plant: the first and second at 2

${ }^{1}$ Contribution No. 33, from the Research Station, Research Branch, Canada Department of Agriculture, Harrow, Ont.

"Present address: Department of Botany, McGill University, Montreal, Que.

"Barren plants of susceptible inbreds and hybrids never have root and stalk rot. Unpublished data. 
weeks and 1 week, respectively, before mid-silk, a third at mid-silk, and four at successive 2 -week intervals thereafter. The stalks were cut at a height of 18 inches, the tops were discarded but the lower stalk and roots were lifted and washed. The roots were detached, weighed into quantities to provide at least 100 grams of dry material, based on previously determined per cent dry matter, and stored in plastic bags in a deep freeze for approximately 2 weeks. The stalks were chopped into small pieces and similarly weighed and stored. For later adjustment of the extraction volume, moisture determinations were made on each sample.

Barren plants of the inbreds were sampled after mid-silk at 2-week intervals. It was hoped to determine if these might have the same biochemical basis of resistance as the genetically resistant plants.

Each sample was boiled in distilled water for 20 minutes and an extract obtained under 15,000-pound pressure by means of a Carver Laboratory Press. The aqueous extract was reduced by boiling to such a volume that the 400-milliliter sample withdrawn for ether extraction represented 100 grams dry matter. This volume, $V$, was derived by the equation

$$
\mathrm{V}=0.04 \mathrm{xy}
$$

where $\mathrm{x}$ is the per cent dry matter, and $\mathrm{y}$ the total weight of the fresh sample. The $\mathrm{pH}$ of the final 400 milliliters was adjusted to 2.5 with $\mathrm{N} \mathrm{HCl}$ and the extraction with ether was made in a liquid-liquid extraction apparatus with 100 milliliters diethyl ether for a period of 6 hours.

In preparation for bio-assay the ether was evaporated from the extract and the residue dissolved in 120 milliliters of boiling distilled water. After filtering this solution through a Buchner filter, 5.9 grams of Difco Czapek's solution agar were dissolved in the filtrate the $\mathrm{pH}$ of which was adjusted to 5.5 with $\mathrm{KH}_{2} \mathrm{PO}_{4}$ or $\mathrm{K}_{2} \mathrm{HPO}_{\text {t. }}$ The medium was then dispensed equally into six test tubes, autoclaved for 20 minutes at 15 pounds' pressure, and poured into petri dishes. The check was Czapek's solution agar alone adjusted to $\mathrm{pH} 5.5$.

Fusarium moniliforme and Gibberella zeae, two known stalk-rotting organisms (10), were used as the test organisms. Inoculum in the form of a square, $2 \times 2$ millimeters, taken always 1 centimeter in from the periphery of PDA cultures of the respective pathogens that had been incubated for 12 days at $25^{\circ} \mathrm{C}$, was transferred to each of three dishes of the prepared media. On the latter, the diameter of each colony was measured after incubation in the dark at $25^{\circ} \mathrm{C}$. for 72 hours. Inhibition of fungus growth by the extract was calculated as per cent of check.

\section{RESULTS AND CONCLUSIONS \\ Effect of Extracts on Growth of F. moniliforme}

The data from the bio-assay of extracts from normal plants in 1959 and 1960 (Figure 1) show that (a) those obtained from the susceptible inbreds (W37A and $\mathrm{CH} 3$ ) exerted the greatest inhibition as frequently as did those from the resistant inbreds (CH9 and $\mathrm{B} 14$ ); and (b) the inhibition by the extracts from each of the four inbreds did not occupy the same relative positions on the graphs in 1960 as in 1959 at any particular developmental 

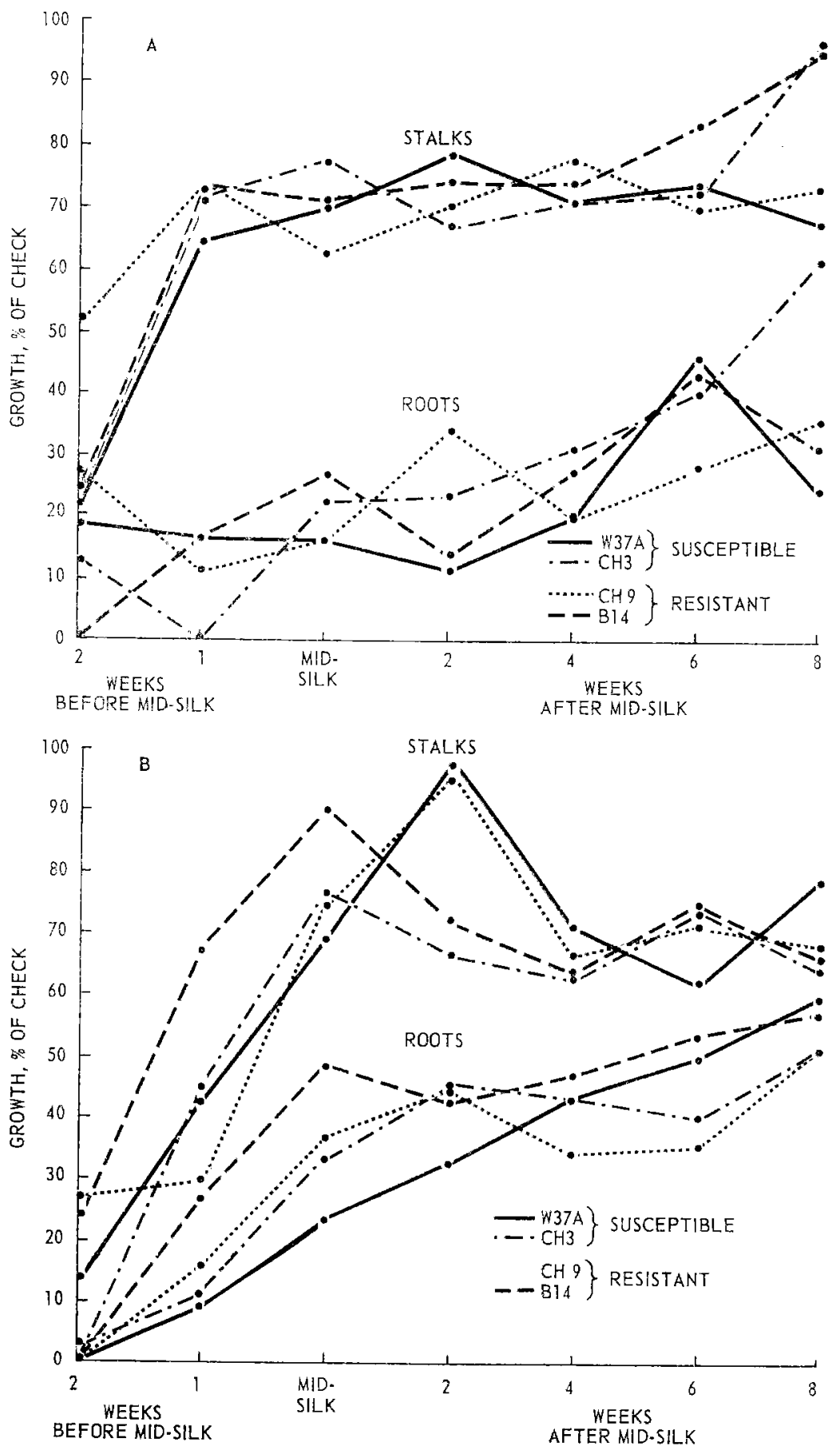

Figure 1. Influence of the ether extracts from the roots and the stalks of normal plants of the four inbreds on growth of $F$. moniliforme. A. 1959, B. 1960. 
stage of the plant. These findings strongly suggest that the ether extracts from the various inbreds do not differ materially in their ability to inhibit fungus growth. Therefore, the resistance in CH9 and B14 cannot be correlated with the inhibitory properties of the ether-soluble compounds from the roots or stalks of these inbreds.

In both years the antifungal activity of the root extracts was greater than that of the stalk but, since this occurred in both susceptible and resistant inbreds, it only demonstrates a higher concentration of antifungal substances in the roots.

Figure 2 presents data of the bio-assay of the extracts from the barren plants. The similarity between this figure and Figure 1 for the common sampling dates is readily evident. These data show that barrenness did not change the inhibitory properties of the ether extracts compared to those from the normal plants. Therefore, since resistance in normal plants could not be correlated with fungal inhibition by ether-soluble extracts, neither can the resistance induced by barrenness be related to the inhibitory properties of the ether-soluble extracts from stalks or roots of barren plants. Effect of Extracts on Growth of G. zeae

On approximately one-half of the sampling dates in both years the results for $G$. zeae paralleled those obtained for $F$. moniliforme for the roots and the stalks of both normal and barren plants. However, inhibition to a greater degree was obtained with $G$. zeae, a circumstance which indicated that this organism was more sensitive to the antifungal properties of the ether extracts. On the other sampling dates the bio-assay showed stimulation of growth by the extracts. This reversal of performance was due to the comparatively slow growth of the fungus on the corresponding check dishes. This abnormal growth of the checks was attributed to slight fluctuations in the $\mathrm{pH}$ of the check media, a circumstance which retarded growth of $G$. zeae when the $\mathrm{pH}$ was below 5.5. The results obtained when growth of the checks was satisfactory supported the conclusions drawn from the results obtained with $F$. moniliforme.

\section{DISCUSSION}

The search for resistance in corn to root and stalk rot involves screening many inbreds. To date the only method to determine resistance is by the examination of mature plants. That method is not satisfactory because of the extended period during which plants within an inbred show symptoms of stalk rot after physiological maturity. A more positive screening technique is desired, preferably one by which plants can be evaluated for resistance prior to physiological maturity.

Since the present bio-assay shows that the ether-soluble substances in the roots and stalks of corn, although they are antifungal, cannot be related to resistance to root and stalk rot, what earlier appeared $(3,8)$ to be possibly a suitable technique is useless in the evaluation of corn for resistance.

Analysis of the extracts by paper chromatography showed that they contained at least four phenolic compounds*. One of these was identified

- Unpublished data 
Figure 2. Influence of the ether extracts from the roots and the stalks of barren plants of the four inbreds on growth of $F$. moniliforme. A. 1959, B, 1960. Extracts for the missing samples were accidentally mishandled during processing and rendered unsuitable for bio-assay.
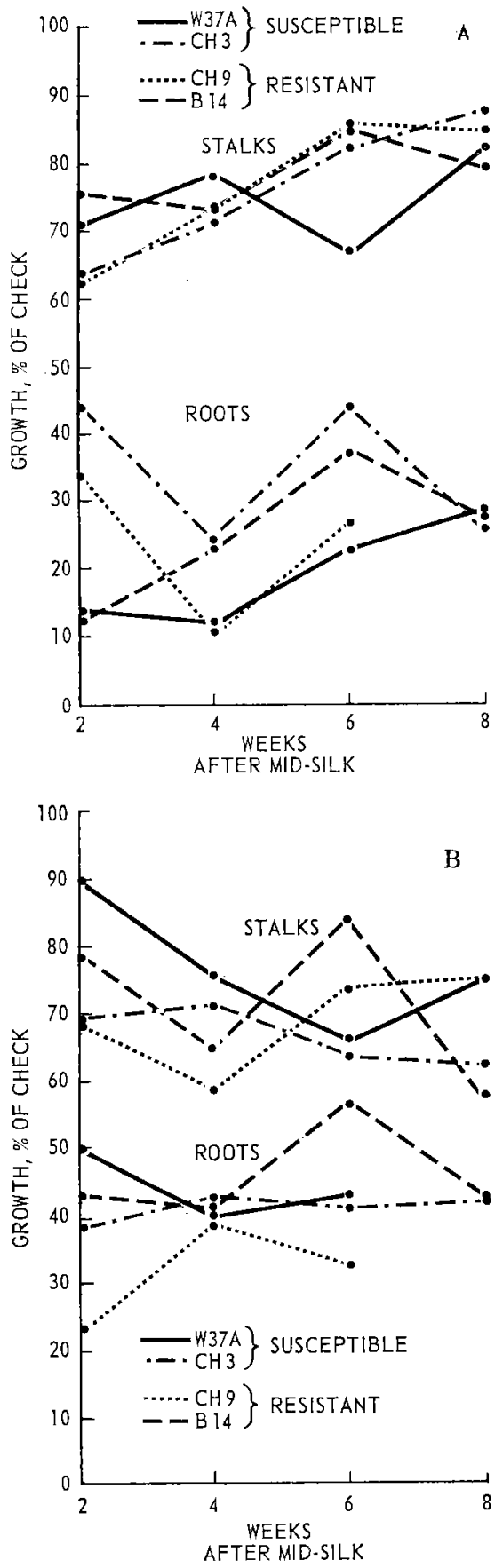
as 6-methoxybenzoxazolinone (MBOA), which Loomis et al. (3) reported as a resistance Factor A. The latter authors also suggested that there were two additional factors, $\mathrm{B}$ and $\mathrm{C}$, in the aqueous extracts which they obtained from corn. These might possibly correspond with two of the other phenolic compounds present in the extracts described in this paper.

The fact that no differences in fungous inhibition were obtained with the ether extracts from susceptible and resistant inbreds suggests that the ether-soluble compounds play no part in the resistance. However, it might well be that the antifungal properties of these compounds are responsible for resistance in the resistant inbreds but are inactivated in the susceptible inbreds by some unknown factor. Perhaps a search should be made for some such "susceptibility factor".

\section{ACKNOWLEDGEMENT}

The authors wish to express their sincere gratitude to $\mathrm{H}$. J. Thorpe, Technician, and A. J. Murray, Plotman, for their faithful and efficient assistance.

\section{REFERENCES}

1. Barnes, J. M. 1959. Extraction and bio-assay of an antifungal substance from inbreds and hybrids of corn differing in susceptibility to Gibberella zede. Phytopathology 49:533.

2. Johann, Helen, and A. D. Dickson. 1945. A soluble substance in cornstalks that retards growth of Diplodia zeae in culture. J. Agr. Research 71:89-110.

3. Loomis, R. S., S. D. Beck, and J. F. Stauffer. 1957. The European corn borer, Pyrausta nubilalis (Hubn.) and its principle host plant. V. A chemical study of host plant resistance. Plant Physiol. 32:379-385.

4. Messiaen, C. M. 1957. Richesse en sucre des tiges des mais et verse parasitaire. Rev. Path. Veg. et Entom. Agr. 36:209-213.

5. Virtanen, A. I., and P. K. Hietala. 1955. 2(3)-Benzoxazolinone, an anti-Fusarium factor in rye seedlings. Acta Chem. Scandinavica 9:1543-1544.

6. Virtanen, A. I., P. K. Hietala, and O. Wahlroos. 1956. An antifungal factor in maize and wheat plants. Suomen Kemistilehti B29:143-144.

7. Whitney, N. J., and C. G. Mortimore. 1957. Root and stalk rot of field corn in southwestern Ontario. I. Sequence of infection and incidence of the disease in relation to maturation of inbred lines. Can. J. Plant Sci. 37:342-346.

8. Whitney, N. J., and C. G. Mortimore. 1959. An antifungal substance in the corn plant and its effect on growth of two stalk-rotting fungi. Nature 183:341.

9. Whitney, N. J., and C. G. Mortimore. 1959. Isolation of the antifungal substance, 6-methoxybenzoxazolinone, from field corn (Zea mays L.) in Canada. Nature 184: 1320.

10. Whitney, N. J., and C. G. Mortimore. 1961. Root and stalk rot of field corn in southwestern Ontario. II. Development of the disease and isolation of organisms. Can. J. Plant Sci. 41:854-861. 